MEDIKA ALKHAIRAAT : JURNAL PENELITIAN KEDOKTERAN DAN KESEHATAN 1(2): 39-45

e-ISSN: 2656-7822, p-ISSN: 2657-179X

\title{
HUBUNGAN GAMBARAN USG DENGAN GEJALA KLINIS PENDERITA NEPHROLITHIASIS YANG DIRAWAT DI RSU ANUTAPURA DAN RSUD UNDATA PALU TAHUN 2018
}

\author{
Ni Ketut Garnis ${ }^{1}$, Mukramin Amran ${ }^{1 *}$, Mohamad Fandy ${ }^{1}$ \\ ${ }^{1}$ Program Studi Pendidikan Dokter, Fakultas Kedokteran Universitas Alkhairat, Jl. Diponegoro No. 39 Palu \\ 94221, Sulawesi Tengah, Indonesia \\ Corresponding author: Telp: +6281524511350
}

\begin{abstract}
ABSTRAK
Di Indonesia, penyakit ginjal yang cukup sering dijumpai antara lain adalah penyakit Nephrolithiasis. Prevalensi penderita nephrolithiasis di Indonesia sebesar 0,6\%. Ginjal merupakan tempat tersering terjadinya batu dibandingkan dengan tempat saluran kemih yang lainnya. Akibat dari batu yang berlokasi diginjal akan memberikan gejala nyeri kolik, hematuria, mual dan muntah serta keluar batu pada saat berkemih. Pemeriksaan USG sebaiknya digunakan sebagai pemeriksaan radiologi yang utama, Pemeriksaan ini sangat efektif dalam mendeteksi lokasi dan ukuran batu pada daerah ginjal. Penelitian ini bertujuan untuk mengetahui hubungan gambaran USG dengan gejala klinis penderita Nephrolithiasis yang di rawat di RSU Anutapura dan RSUD Undata Palu Tahun 2018. Penelitian ini bersifat observasional analitik dengan design study cross sectional. Pengambilan sampel dilakukan secara consecutive sampling. Pengumpulan data dilakukan dengan wawancara menggunakan kuesioner dan case report pada pasien nephrolithiasis. Analisis data menggunakan SPSS 21 dengan uji chi-square, uji Kruskal-Wallis dan uji Fisher's pada batas kemaknaan $\alpha=5 \%$. Hasil penelitian yakni ditemukan nyeri kolik berhubungsn dengan lokasi kaliks ( $\mathrm{p}=0,013$ ), hematuria berhubungan dengan lokasi pelvic $(\mathrm{p}=0,000)$, mual dan muntah berhubungan dengan lokasi kaliks $(\mathrm{p}=0,021)$, batu saat berkemih berhubungan dengan lokasi pelvic ( $\mathrm{p}=0,008)$, dan ukuran batu <10MM berhubungan dengan adanya batu saat berkemih ( $\mathrm{p}=0,033$; OR 0,373). Tidak ditemukan hubungan yang bermakna ( $>0,05)$ antara ukuran batu dengan gejala nyeri kolik, hematuria, mual dan muntah. Disimpulkan bahwa ada hubungan antara lokasi dengan gejala klinis nyeri kolik, hematuria, mual dan muntah, batu saat berkemih, serta ada hubungan antara ukuran batu dengan gejala batu saat berkemih.
\end{abstract}

Kata kunci : USG, Nephrolithiasis, Penyakit Ginjal

\section{ABSTRACT}

In Indonesia, kidney disease, which is quite common, is Nephrolithiasis. The prevalence of nephrolithiasis patients in Indonesia is $0.6 \%$. The kidney is the most common place of stone compared to the other urinary tract. As a result of the stones that are located in the kidney, it will give symptoms of colic pain, haematuria, nause and vomiting and out of stone when urinating. Ultrasound examination should be used as the main radiological examination, this examination is very effective in detecting the location and size of stones in the kidney area. This study aimed to determine the relationship of ultrasound images with clinical symptoms of Nephrolithiasis patients treated at Anutapura Hospital and Undata Palu Hospital in 2018. This study was observational analytic with a cross sectional study design. Sampling was done by consecutive sampling. Data collection was carried out by interviewing questionnaires and case reports in nephrolithiasis patients. Data analysis using SPSS 21 with the chi-square test, Kruskal-Wallis test and Fisher's test on the significance limit $\alpha=5 \%$. The results of the study were that colic pain was associated with the location of the calix ( $p=0.013)$, hematuria associated with the location of the pelvic $(p=0,000)$, nausea and vomiting associated with the location of the calix $(p=0.021)$, stone urination $(p=0.008)$, and stone size <10MM is associated with the presence of stones when urinating $(p=0.033$; OR 0.373). No significant relationship was found $(p>0.05)$ between stone size and symptoms of colic pain, haematuria, nausea and vomiting. It was concluded that there was a relationship between the location with clinical symptoms of colic pain, 
haematuria, nausea and vomiting, stones when urinating, and there was a relationship between the size of the stone and the symptoms of stones when urinating.

Keywords: Ultrasound, Nephrolithiasis, Kidney Disease

\section{PENDAHULUAN}

Nephrolithiasis adalah gangguan urologi yang di sebabkan oleh pengendapan substansi yang mengandung komponen Kristal dan matriks organik dalam air kemih atau zat-zat sisa hasil sekresi tubuh yang jumlahnya berlebihan mengendap di dalam pelvis atau kaliks ginjal. ${ }^{1}$

Prevalensi dan kejadian nephrolithiasis di laporkan meningkat secara global. Peningkatan ini terlihat pada semua jenis kelamin, Ras dan usia (Romero, 2010). Kejadian Nephrolithiasis meningkat setelah usia 20 tahun, mencapai puncak antara usia 40-60 tahun (Sakhaee, 2012).

Penyakit ginjal di Indonesia yang cukup sering dijumpai antara lain adalah penyakit Nephrolithiasis. Prevalensi penderita nephrolithiasis di Indonesia sebesar 0,6\%. Berdasarkan laporan 33 provinsi, terdapat lima provinsi dengan cakupan nephrolithiasis tertinggi berturut turut ialah provinsi DI Yogyakarta sebesar 1,2\%, diikuti Aceh 0,9\%, Jawa Barat, Jawa Tengah, dan Sulawesi Tengah masing-masing sebesar 0,8\% (Kementrian Kesehatan Republik Indonesia, 2013 : 94-96), ${ }^{2}$ dan jumlah kasus nephrolithiasis di RSU Anutapura tahun 2014 sampai 2017 berturut-turut ialah 194, 298, 310, dan 263 kasus dan RSUD Undata tahun 2014 sampai 2017 berturut turut ialah 85, 42, 82, dan 148 Kasus (Data Rekam Medik, RSU Anutapura Palu; 2018 serta Data Rekam Medik RSUD Undata Palu; 2018). ${ }^{3,4}$

Lokasi dari batu bisa terkena dibeberapa tempat yaitu diginjal, ureter dan kandung kemih. Ginjal merupakan tempat tersering terjadinya batu dibandingkan dengan tempat saluran kemih yang lainnya. Akibat dari batu yang berlokasi diginjal adalah nyeri pada pinggang kearah bawah dan depan, nyeri ini mungkin bisa berupa nyeri kolik ataupun bukan kolik, hematuria juga sering kali dikeluhkan oleh pasien akibat trauma pada mukosa saluran kemih yang disebabkan oleh batu, mual dan muntah serta adanya batu pada saat BAK dan pada saat melakukan pemeriksaan USG akan terdapat gambaran batu pada daerah ginjal. ${ }^{5}$

$$
\text { Pemeriksaan Ultrasonografi }
$$
sebaiknya digunakan sebagai pemeriksaan radiologi yang utama, Pemeriksaan ini sangat efektif dalam menilai ukuran ginjal, pertumbuhan, massa, serta obstruksi pada ginjal.(Ricardo Ahmad, 2013). Pada penilaian nephrolithiasis yang penting diperhatikan adalah: (a) Jumlah, (b) densitas dan bayangan, (c) lokasi, (d) ukuran, (e) terjadinya anomaly dan (f) nefrokalsinosis. ${ }^{6}$

\section{METODOLOGI}

Desain penelitian yang digunakan adalah metode analitik dengan pendekatan cross sectional yang bertujuan untuk mengetahui hubungan lokasi dan ukuran batu berdasarkan hasil Gambaran USG dengan gambaran klinis nyeri kolik, hematuria, mual dan muntah dan adanya batu saat berkemih pada penderita Nephrolithiasis. Waktu Penelitian dilakukan pada 10 April - 10 Juni 2018, Tempat penelitian di poliklinik penyakit dalam RSU Anutapura Palu dan dibagian urologi RSUD Undata Palu.

\section{Populasi}

Seluruh pasien yang telah di diagnosis oleh dokter dirawat jalan di poliklinik penyakit dalam RSU Anutapura Palu dan bagian urologi RSUD Undata Palu pada tahun 2018 yang memenuhi kriteria penelitian.

\section{Sampel}

Menentukan besar sampel dengan menggunakan rumus besar sampel penelitian analitik cross sectional adalah sebagai berikut:

$$
\mathrm{n}=\frac{z_{1-}^{2} \propto / 2 P(1-p) N}{d^{2}(N-1)+z_{1-}^{2} \propto_{/ 2} p(1-p)}
$$

Dengan perhitungan berdasarkan rumus di atas, didapatkan nilai $\mathrm{n}=83$. Jadi, sampel dalam penelitian adalah 83 orang. Tehnik pengambilan 
sampel yang digunakan pada penelitian ini adalah consecutive sampling yaitu semua pasien yang telah di diagnosis oleh dokter menderita penyakit nephrolithiasis dan melakukan pemeriksaan USG.

\section{Analisis Data}

Penelitian ini diolah dengan menggunakan perangkat lunak komputer program SPSS 21.0. kemudian dilakukan analisis data yang digunakan untuk mengetahui hubungan gambaran USG dengan gejala klinis pada penderita nephrolithiasis menggunakan analisis (digunakan untuk mencari hubungan 2 variabel) yaitu dengan metode chi square dan Kruskal Wallis.

\section{HASIL DAN PEMBAHASAN}

Gambaran hasil USG nephrolithiasis dengan gejala klinis (Nyeri kolik, hematuria, mual dan muntah, keluar batu saat berkemih) dapat dilihat pada tabel berikut ini:

a. Hubungan lokasi nephrolithiasis dengan gejala klinis nyeri kolik

Mengidentifikasi hubungan lokasi nephrolithiasis dengan gejala klinis nyeri kolik, dilakukan uji Kruskal-Wallis dan didapatkan hasil sebagaimana pada tabel 1 .

Tabel 1. Hubungan Lokasi Nephrolithiasis berdasarkan hasil USG dengan Gejala Klinis Nyeri Kolik di RSU Anutapura dan RSU Undata Palu tahun 2018.

\begin{tabular}{|l|c|c|c|}
\hline \multirow{2}{*}{ Lokasi batu } & \multicolumn{2}{|c|}{ Nyeri Kolik } & \multirow{2}{*}{ P } \\
\cline { 2 - 3 } & $\begin{array}{c}\text { Ada } \\
\text { Nyeri }\end{array}$ & $\begin{array}{c}\text { Tidak Ada } \\
\text { Nyeri }\end{array}$ & \\
\hline Kaliks & $\begin{array}{c}36 \\
(100.0 \%)\end{array}$ & $\begin{array}{c}0 \\
(0.0 \%)\end{array}$ & \multirow{2}{*}{0,013} \\
\cline { 1 - 3 } Infundibulum & $\begin{array}{c}23 \\
(85.2 \%)\end{array}$ & $\begin{array}{c}4 \\
(14.8 \%)\end{array}$ & \\
\hline Pelvic & $\begin{array}{c}20 \\
(100.0 \%)\end{array}$ & $\begin{array}{c}0 \\
(0.0 \%)\end{array}$ & \\
\hline Total & $\begin{array}{c}79 \\
(95.2 \%)\end{array}$ & $\begin{array}{c}4 \\
(4.8 \%)\end{array}$ & \\
\hline
\end{tabular}

b. Hubungan lokasi nephrolithiasis dengan gejala klinis hematuria

Mengidentifikasi hubungan lokasi nephrolithiasis dengan gejala klinis hematuria, dilakukan uji Kruskal-Wallis dan didapatkan hasil pada tabel 2 .

Tabel 2. Hubungan lokasi nephrolithiasis berdasarkan hasil USG dengan gejala klinis hematuria di RSU Anutapura dan RSUD Undata Palu Tahun 2018

\begin{tabular}{|l|c|c|c|}
\hline \multirow{2}{*}{ Lokasi batu } & \multicolumn{2}{|c|}{ Hematuria } & \multirow{2}{*}{ P } \\
\cline { 2 - 3 } & $\begin{array}{c}\text { Ada } \\
\text { Hematuria }\end{array}$ & $\begin{array}{c}\text { Tidak Ada } \\
\text { Hematuria }\end{array}$ & \\
\hline Kaliks & $\begin{array}{c}5 \\
(13.9 \%)\end{array}$ & $\begin{array}{c}31 \\
(86.1 \%)\end{array}$ & \\
\cline { 1 - 3 } Infundibulum & $\begin{array}{c}8 \\
(29.6 \%)\end{array}$ & $\begin{array}{c}19 \\
(70.4 \%)\end{array}$ & \multirow{2}{*}{0,000} \\
\hline Pelvic & $\begin{array}{c}13 \\
(65.0 \%)\end{array}$ & $\begin{array}{c}7 \\
(35.0 \%)\end{array}$ & \\
\hline Total & $\begin{array}{c}26 \\
(31.3 \%)\end{array}$ & $\begin{array}{c}57 \\
(68.7 \%)\end{array}$ & \\
\hline
\end{tabular}

c. Hubungan lokasi nephrolithiasis dengan gejala klinis mual dan muntah

Mengidentifikasi hubungan lokasi nephrolithiasis dengan gejala klinis mual dan muntah, dilakukan uji Kruskal-Wallis dan didapatkan hasil pada tabel 3.

Tabel 3. Hubungan lokasi nephrolithiasis berdasarkan hasil USG dengan gejala klinis mual dan muntah di RSU Anutapura dan RSUD Undata Palu Tahun 2018

\begin{tabular}{|l|c|c|c|}
\hline \multirow{2}{*}{ Lokasi batu } & \multicolumn{2}{|c|}{ Mual dan Muntah } & \multirow{2}{*}{ P } \\
\cline { 2 - 3 } & Ada & $\begin{array}{c}\text { Tidak } \\
\text { Ada }\end{array}$ & \\
\hline Kaliks & $\begin{array}{c}25 \\
(69.4 \%)\end{array}$ & $\begin{array}{c}11 \\
(30.6 \%)\end{array}$ & \\
\hline $\begin{array}{l}\text { Infundibulu } \\
\mathrm{m}\end{array}$ & $\begin{array}{c}14 \\
(51.9 \%)\end{array}$ & $\begin{array}{c}13 \\
(48.1 \%)\end{array}$ & \multirow{2}{*}{0,000} \\
\hline Pelvic & $\begin{array}{c}18 \\
(90.0 \%)\end{array}$ & $\begin{array}{c}2 \\
(10.0 \%)\end{array}$ & \\
\hline Total & $\begin{array}{c}57 \\
(68.7 \%)\end{array}$ & $\begin{array}{c}26 \\
(31.3 \%)\end{array}$ & \\
\hline
\end{tabular}


MEDIKA ALKHAIRAAT : JURNAL PENELITIAN KEDOKTERAN DAN KESEHATAN 1(2): 39-45

e-ISSN: 2656-7822, p-ISSN: 2657-179X

d. Hubungan lokasi nephrolithiasis dengan gejala klinis batu saat berkemih

Mengidentifikasi hubungan lokasi nephrolithiasis dengan gejala klinis batu saat berkemih, dilakukan uji Kruskal-Wallis dan didapatkan hasil pada tabel 4.

Tabel 4. Hubungan lokasi nephrolithiasis berdasarkan hasil USG dengan gejala klinis batu saat berkemih di RSU Anutapura dan RSUD Undata Palu Tahun 2018

\begin{tabular}{|l|c|c|c|}
\hline \multirow{2}{*}{ Lokasi batu } & \multicolumn{2}{|c|}{ Mual dan Muntah } & \multirow{2}{*}{ P } \\
\cline { 2 - 3 } & Ada & $\begin{array}{c}\text { Tidak } \\
\text { Ada }\end{array}$ & \\
\hline Kaliks & $\begin{array}{c}9 \\
(25.0 \%)\end{array}$ & $\begin{array}{c}27 \\
(75.0 \%)\end{array}$ & \multirow{2}{*}{0.008} \\
\hline Infundibulum & $\begin{array}{c}8 \\
(29.6 \%)\end{array}$ & $\begin{array}{c}19 \\
(70.4 \%)\end{array}$ & \\
\hline Pelvic & $\begin{array}{c}13 \\
(65.0 \%)\end{array}$ & $\begin{array}{c}7 \\
(35.0 \%)\end{array}$ & \\
\hline Total & $\begin{array}{c}30 \\
(36.1 \%)\end{array}$ & $\begin{array}{c}53 \\
(63.9 \%)\end{array}$ & \\
\hline
\end{tabular}

e. Hubungan ukuran nephrolithiasis dengan gejala klinis nyeri kolik

Mengidentifikasi hubungan lokasi nephrolithiasis dengan gejala klinis nyeri kolik, dilakukan crosstabulasi dan dihitung nilai $\mathrm{P}$ berdasarkan uji Fisher's yang hasilnya dapat dilihat pada tabel 5 .

Tabel 5. Hubungan ukuran nephrolithiasis berdasarkan hasil USG dengan gejala klinis nyeri kolik di RSU Anutapura dan RSUD Undata Palu Tahun 2018.

\begin{tabular}{|c|c|c|c|c|}
\hline \multirow[b]{2}{*}{ Ukuran Batu } & \multicolumn{2}{|c|}{ Nyeri Kolik } & \multirow[b]{2}{*}{$\mathrm{P}$} & \multirow[b]{2}{*}{ OR } \\
\hline & $\begin{array}{l}\text { Ada } \\
\text { Nyeri } \\
\text { Kolik }\end{array}$ & $\begin{array}{c}\text { Tidak } \\
\text { Ada } \\
\text { Nyeri } \\
\text { Kolik }\end{array}$ & & \\
\hline$>10 \mathrm{MM}$ & $\begin{array}{c}43 \\
(93.5 \%)\end{array}$ & $\begin{array}{c}3 \\
(6.5 \%)\end{array}$ & & \multirow{3}{*}{0,398} \\
\hline$<10 \mathrm{MM}$ & $\begin{array}{c}36 \\
(97.3 \%)\end{array}$ & $\begin{array}{c}1 \\
(2.7 \%)\end{array}$ & 0,625 & \\
\hline Total & $\begin{array}{c}79 \\
(95.2 \%)\end{array}$ & $\begin{array}{c}4 \\
(4.8 \%)\end{array}$ & & \\
\hline
\end{tabular}

f. Hubungan ukuran nephrolithiasis dengan gejala klinis hematuria

Mengidentifikasi hubungan lokasi nephrolithiasis dengan gejala klinis hematuria, dilakukan crosstabulasi dan dihitung nilai $\mathrm{P}$ berdasarkan uji Chi-Square yang hasilnya dapat dilihat pada tabel 6 .

Tabel 6. Hubungan ukuran nephrolithiasis berdasarkan hasil USG dengan gejala klinis hematuria di RSU Anutapura dan RSUD Undata Palu Tahun 2018.

\begin{tabular}{|l|c|c|c|c|}
\hline \multirow{2}{*}{$\begin{array}{c}\text { Ukuran } \\
\text { Batu }\end{array}$} & \multicolumn{2}{|c|}{ Nyeri Kolik } & \multirow{2}{*}{ P } & \multirow{2}{*}{ OR } \\
\cline { 2 - 3 } & Ada & $\begin{array}{c}\text { Tidak } \\
\text { Ada }\end{array}$ & & \\
\hline$>10 \mathrm{MM}$ & $\begin{array}{c}15 \\
(32.6 \%)\end{array}$ & $\begin{array}{c}31 \\
(67.4 \%)\end{array}$ & & \\
\hline$<10 \mathrm{MM}$ & $\begin{array}{c}11 \\
(29.7 \%)\end{array}$ & $\begin{array}{c}26 \\
(70.3 \%)\end{array}$ & \begin{tabular}{c}
0,77 \\
\multirow{2}{*}{ < }
\end{tabular} & \multirow{2}{*}{1,144} \\
\hline Total & $\begin{array}{c}26 \\
(31.3 \%)\end{array}$ & $\begin{array}{c}57 \\
(68.7 \%)\end{array}$ & & \\
\hline
\end{tabular}

g. Hubungan ukuran nephrolithiasis dengan gejala klinis mual dan muntah

Mengidentifikasi hubungan lokasi nephrolithiasis dengan gejala klinis mual dan muntah, dilakukan crosstabulasi dan dihitung nilai $\mathrm{P}$ berdasarkan uji Chi-Square yang hasilnya dapat dilihat pada tabel 7 .

Tabel 7. Hubungan ukuran nephrolithiasis berdasarkan hasil USG dengan gejala klinis mual dan muntah di RSU Anutapura dan RSUD Undata Palu Tahun 2018.

\begin{tabular}{|c|c|c|c|c|}
\hline \multirow[b]{2}{*}{ Ukuran Batu } & \multicolumn{2}{|c|}{ Mual dan Muntah } & \multirow[b]{2}{*}{$\mathrm{P}$} & \multirow[b]{2}{*}{ OR } \\
\hline & $\begin{array}{c}\text { Ada } \\
\text { Mual } \\
\text { dan } \\
\text { Muntah }\end{array}$ & $\begin{array}{c}\text { Tidak } \\
\text { Ada } \\
\text { Mual } \\
\text { dan } \\
\text { Muntah }\end{array}$ & & \\
\hline$>10 \mathrm{MM}$ & $\begin{array}{c}31 \\
(67.4 \%)\end{array}$ & $\begin{array}{c}15 \\
(32.6 \%)\end{array}$ & \multirow{3}{*}{0,779} & \multirow{3}{*}{0,874} \\
\hline$<10 \mathrm{MM}$ & $\begin{array}{c}26 \\
(70.3 \%)\end{array}$ & $\begin{array}{c}11 \\
(29.7 \%)\end{array}$ & & \\
\hline Total & $\begin{array}{c}57 \\
(68.7 \%)\end{array}$ & $\begin{array}{c}26 \\
(31.3 \%)\end{array}$ & & \\
\hline
\end{tabular}




\section{h. Hubungan ukuran nephrolithiasis dengan gejala} klinis batu saat berkemih

Mengidentifikasi hubungan lokasi nephrolithiasis dengan gejala klinis batu saat berkemih, dilakukan crosstabulasi dan dihitung nilai $\mathrm{P}$ berdasarkan uji Chi-Square yang hasilnya dapat dilihat pada tabel 8 .

Tabel 8. Hubungan ukuran nephrolithiasis berdasarkan hasil USG dengan gejala klinis batu saat berkemih di RSU Anutapura dan RSUD Undata Palu Tahun 2018

\begin{tabular}{|l|c|c|c|c|}
\hline \multirow{2}{*}{$\begin{array}{c}\text { Ukura } \\
\text { n Batu }\end{array}$} & \multicolumn{2}{|c|}{ Batu Saat } & \multirow{3}{*}{ Berkemih } & \multirow{2}{*}{ OR } \\
\cline { 2 - 3 } & Ada & $\begin{array}{c}\text { Tidak } \\
\text { Ada }\end{array}$ & & \\
\hline$>10$ & 12 & 34 & & \\
MM & $(26.1 \%)$ & $(73.9 \%)$ & & \\
\hline$<10$ & 18 & 19 & 0,03 & \multirow{2}{*}{0,373} \\
MM & $(48.6 \%)$ & $(51.4 \%)$ & 3 & \\
\hline Total & $\begin{array}{c}30 \\
(36.1 \%)\end{array}$ & $\begin{array}{c}53 \\
(63.9 \%)\end{array}$ & & \\
\hline
\end{tabular}

Sumber: Data olahan, 2018.

\section{Hubungan Lokasi Nephrolithiasis dengan Gejala Klinis Nyeri Kolik}

Berdasarkan uji statistik menggunakan program SPSS versi 21.0 diperoleh hasil yang bermakna dimana $\mathrm{P}=0.013 \quad(\mathrm{P}<0,05) \quad$ sehingga diperoleh kesimpulan bahwa lokasi batu mempunyai hubungan yang bermakna dengan gejala klinis nyeri kolik pada penderita nephrolithiasis di RSU Anutapura dan RSUD Undata Palu. Nyeri kolik terjadi karena aktivitas peristaltik otot polos sistem kalises ataupun ureter meningkat dalam usaha untuk mengeluarkan batu dari saluran kemih, peningkatan peristaltik itu menyebabkan tekanan intraluminalnya meningkat sehingga terjadi peregangan dari terminal saraf di illioinguinal dan cabang saraf geniformis yang memberikan sensasi nyeri oleh terjadinya obstruksi batu pada ginjal ataupun saluran kemih yang ditandai dengan serangan nyeri pinggang menyebar ke arah lipat paha.

\section{Hubungan Lokasi Nephrolithiasis dengan Gejala} Klinis Hematuria

Berdasarkan uji statistik menggunakan program SPSS versi 21.0 diperoleh hasil yang bermakna dimana $\mathrm{P}=0,000 \quad(\mathrm{P}<0,05) \quad$ sehingga diperoleh kesimpulan bahwa lokasi batu mempunyai hubungan yang bermakna dengan gejala klinis hematuria pada penderita nephrolithiasis di RSU Anutapura dan RSUD Undata Palu. Batu yang terperangkap di dalam ureter (kolik ureter) sering mengalami desakan berkemih, tetapi hanya sedikit urin yang keluar. Keadaan ini akan menimbulkan gesekan yang disebabkan oleh batu sehingga urin yang dikeluarkan bercampur dengan darah (hematuria).

\section{Hubungan lokasi nephrolithiasis dengan gejala klinis mual dan muntah}

Berdasarkan uji statistik menggunakan program SPSS versi 21.0 diperoleh hasil yang bermakna dimana $\mathrm{P}=0,021 \quad(\mathrm{P}<0,05) \quad$ sehingga diperoleh kesimpulan bahwa lokasi batu mempunyai hubungan yang bermakna dengan gejala klinis mual dan muntah pada penderita nephrolithiasis di RSU Anutapura dan RSUD Undata Palu.

Sesuai teori obstruksi pada saluran kemih bagian atas sering dikaitkan dengan terjadinya gejala mual dan muntah. Kondisi ini merupakan efek samping dari kondisi ketidaknyamanan pada pasien karena nyeri yang sangat hebat sehingga pasien mengalami stress yang tinggi dan memacu sekresi $\mathrm{HCl}$ pada lambung. dari berbagai studi menyatakan bahwa nyeri mendadak yang bersifat tajam, terasa melilit, hilang timbul, tidak berkurang dengan perubahan posisi, penderita dapat gelisah sampai berguling-guling di tempat tidur, serta kadang disertai mual dan muntah.

\section{Hubungan Lokasi Nephrolithiasis dengan gejala klinis batu saat berkemih}

Berdasarkan statistik menggunakan program SPSS versi 21.0 diperoleh hasil yang bermakna dimana $\mathrm{P}=0,008 \quad(\mathrm{P}<0,05) \quad$ sehingga diperoleh 
kesimpulan bahwa lokasi batu mempunyai hubungan yang bermakna dengan gejala klinis batu saat berkemih pada penderita nephrolithiasis di RSU Anutapura dan RSUD Undata Palu. Hal ini dikarenakan batu dengan ukuran kecil mungkin dapat keluar secara spontan setelah melalui hambatan pada perbatasan uretero-pelvik, saat ureter menyilang vasa iliaka dan saat ureter masuk ke dalam buli-buli.

\section{Hubungan Ukuran Nephrolithiasis dengan gejala klinis nyeri kolik}

Berdasarkan hasil penelitian berdasarkan gejala nyeri kolik pada ukuran batu hasil USG nephrolithiasis lebih banyak ditemukan pada ukuran >10mm (93.5\%), setelah dihubungkan ukuran nephrolithiasis dengan gejala klinis nyeri kolik di dapatkan hasil uji statistic menggunakan SPSS diperoleh nilai $\mathrm{P}$ yaitu $0.625(\mathrm{P}>0,05)$. Di simpulkan bahwa tidak ada hubungan yang bermakna antara nyeri kolik dengan ukuran batu.

Sesuai teori Ukuran dan bentuk batu pada penderita nephrolithiasis menimbulkan gejala yang berbeda sesuai letak dan ukuran batu tersebut. Batu yang berukuran kecil biasanya tidak menimbulkan gejala dan biasanya dapat keluar bersamaan dengan air kemih saat berkemih. Batu yang berada di saluran kemih atas (ginjal dan ureter) menimbulkan nyeri kolik dan jika batu berada di saluran kemih bagian bawah (buli-buli dan uretra) dapat menghambat berkemih. Hal ini bisa disebabkan karena kontraksi peristaltik otot-otot saluran kemih terhadap batu yang dapat menimbulkan rasa nyeri kolik yang hebat.

\section{Hubungan Ukuran Nephrolithiasis dengan Gejala Klinis Hematuri}

Berdasarkan hasil penelitian berdasarkan gejala hematuria pada ukuran batu hasil USG nephrolithiasis lebih banyak ditemukan pada ukuran >10mm (32.6\%) setelah dihubungkan ukuran nephrolithiasis dengan gejala klinis hematuria di dapatkan hasil uji statistic menggunakan SPSS diperoleh nilai P yaitu 0.779
( $P>0,05)$. Di simpulkan bahwa tidak ada hubungan yang bermakna antara hematuria dengan ukuran batu.

Sesuai teori Proses agregasi kristal terjadi pengikatan antara kristal yang satu dengan yang lainya sehingga semakin besar. Kemudian terjadi retensi kristal di mukosa saluran kemih. Kristal akan bertahan di mukosa. Setelah ada aliran urin yang akan mendorong kristal ke saluran kemih, maka kristal akan menyumbat saluran tersebut. Itu semua besarnya ukuran kristal. Namun, jika ukuranya telah sama dengan diameter lumen maka akan terbentuk obstruksi saluran kemih. Sambil terbawa oleh aliran kemih, bentuk dari kristal yang terbentuk juga mampu mengiritasi mukosa saluran kemih. Bahkan tidak jarang akan membuat perdarahan kecil. Maka dalam temuan klinis didapatkan hematuria.

\section{Hubungan Ukuran Nephrolithiasis dengan Gejala Klinis Mual dan Muntah \\ Berdasarkan hasil penelitian berdasarkan} gejala mual dan muntah pada ukuran batu hasil USG nephrolithiasis lebih banyak ditemukan pada ukuran >10mm (67.4\%) setelah dihubungkan ukuran nephrolithiasis dengan gejala klinis mual dan muntah di dapatkan hasil uji statistic menggunakan SPSS diperoleh nilai P yaitu 0.779 $(\mathrm{P}>0,05)$. Di simpulkan bahwa tidak ada hubungan yang bermakna antara mual dan muntah dengan ukuran batu. Sesuai teori mual dan muntah terjadi karena adanya nyeri kolik yang hebat, Kondisi ini merupakan efek samping dari kondisi ketidaknyamanan pada pasien karena nyeri yang sangat hebat sehingga pasien mengalami stress yang tinggi dan memacu sekresi $\mathrm{HCl}$ pada lambung (Brooker, 2009). Selain itu, hal ini juga dapat disebabkan karena adanya stimulasi dari celiac plexus, namun gejala gastrointestinal biasanya tidak ada.

\section{Hubungan Ukuran Nephrolithiasis dengan Gejala Klinis Batu Saat Berkemih \\ Berdasarkan hasil penelitian berdasarkan gejala batu saat berkemih pada ukuran batu hasil}


USG nephrolithiasis lebih banyak ditemukan pada ukuran <10mm (48.6\%), setelah dihubungkan ukuran nephrolithiasis dengan gejala klinis batu saat berekemih di dapatkan hasil uji statistic menggunakan SPSS diperoleh nilai $P$ yaitu 0.033 $(\mathrm{P}<0,05)$. Di simpulkan bahwa terdapat hubungan bermakna antara batu saat berkemih dengan lokasi batu.

Secara umum, batu yang berukuran kecil dengan diameter maksimal 4-5 mm akan mampu melewati ureter dan biasanya mampu keluar bersama urine, sedangkan batu yang berukuran lebih besar akan tersangkut dipelvis ginjal yang menyebabkan obstruksi dan menjadi penyebab terjadinya hidronefrosis bahkan kerusakan dari ginjal.

\section{DAFTAR PUSTAKA}

1. Asplin, et.al, 2013. Nefrolitiasis. Nefrologi dan Gangguan Asam Basa. EGC, Jakarta.

2. Kementrian Kesehatan RI, 2017. Laporan Riset Kesehatan Dasar 2013. Badan Penelitian dan Pengembangan Kesehatan Kementrian Kesehatan Republik Indonesia, Jakarta

3. RSU Anutapura Palu, 2018. Data Rekam Medik 2018. RSU Anutapura, Palu.

4. RSUD Undata Palu, 2018. Data Rekam Medik 2018. RSUD Undata, 2018.

5. Purnomo, 2014. Batu Saluran Kemih, DasarDasar Urologi. Sagung Seto, Malang.

6. Budjang, 2008. Radiologi Diagnostik Edisi 2. Balai Penerbit FK UI, Jakarta. 